\title{
Perceived justice and recovery satisfaction: the moderating role of customer-perceived quality
}

\author{
Subhash JHA \\ Indian Institute of Management, Udaipur, India \\ M.S. BALAJI \\ Taylor's University, Selangor, Malaysia
}

\begin{abstract}
Recovery strategies are critical to service providers in their efforts to maintain satisfied and loyal customers. While the existing research shows that recovery satisfaction is a function of customer perception of distributive, procedural and interactional justice, the present study considers an important contextual factor - customer-perceived quality of the service provider in the evaluation of justice dimensions and satisfaction. To test the hypotheses proposed, a survey was carried out in the mobile services context. The findings reveal that customer-perceived quality affects the evaluation of justice dimensions and its outcomes. The findings reveal that while distributive justice enhances recovery satisfaction for low perceived quality services, the procedural justice resulted in greater satisfaction in high perceived quality services. Thus, by understanding the role of customer-perceived quality, service managers can deliver effective recovery strategies thereby enhancing satisfaction and loyalty.
\end{abstract}

Keywords: customer-perceived quality, service failure, distributive justice, procedural justice, recovery satisfaction.

Please cite the article as follows: Jha, S. and Balaji, M.S. (2015), "Perceived justice and recovery satisfaction: the moderating role of customer-perceived quality", Management \& Marketing. Challenges for the Knowledge Society, Vol. 10, No. 2, pp. 132-147, DOI: 10.1515/mmcks-2015-0011.

\section{Introduction}

As service failures are inevitable, recovery strategies have become a prominent issue for managers (McCollough et al., 2000; Kau and Loh, 2006). A number of researchers have utilized justice theory to examine the role of distributive justice, procedural justice and interactional justice in alleviating the negative effects of service failure (McColl-Kennedy and Sparks, 2003; Wang et al., 2011). It was argued that when recovery efforts are successful, customers become more satisfied and willing to repurchase (Blodgett, Hill and Tax, 1997). Moreover, perceived justice leads to positive emotions, trust, and future compliance behavior (Schoefer and Ennew, 2005; DeWit et al., 2008). Thus, effective service recovery leads to customer satisfaction and aids in maintaining a positive relationship with them (Fang et al., 2012). However, prior studies suggest that customers' justice perceptions are influenced by various contextual factors (Matilla, 2001; de Matos et al., 2012; Sengupta et al., 2014). Thus, an understanding of these contextual factors aids managers in delivering suitable and successful recovery strategies.

In the present study, we consider the role of "customer-perceived quality", a contextual factor in customer evaluation of perceived justice and recovery satisfaction. Customer-perceived quality refers to the overall quality assessment of 
the service provider based on his/her past experiences. In other words it is customers' apriori quality perception of the service provider before encountering the service failure. Extant research indicates that customer assessment of the service provider might influence the evaluation of service failure and recovery efforts (Smith and Bolton, 1998; Kim et al., 2012). Despite this, to date, very little research - if any - has examined the impact of customer perceived quality within a failure/recovery context. Moreover, the studies relating to the relationship between service failure severity, perceived justice and recovery satisfaction have been contrasting. To address this gap in the literature, the present study relies on the expectancy-disconfirmation theory and mental accounting theory to examine the role of customer-perceived quality (apriori service quality) in the examining the relationships between perceived justice dimensions, service failure severity, recovery satisfaction and loyalty. Specifically, this study attempts to address the following research question: whether customer-perceived quality affects the relationship between failure severity, perceived justice dimensions and satisfaction.

\section{Literature review Perceived justice}

Perceived justice refers to the level of "fairness" or "rightness" of the recovery efforts (de Matos et al., 2012). Prior literature shows that the way in which the customers perceive and evaluate the recovery efforts impact their attitude and behaviors (Weun et al., 2004). A meta-analysis by Orsingher et al. (2010) reported that the three dimensions of justice - distributive, procedural and interactional justice explain the customers' perception of satisfaction with the service recovery. Distributive justice deals with the perceived equity, such that outcomes (gains) are allocated in proportion to the relevant costs (inputs) of the service failure (Lin et al., 2011). It refers to the fairness of resource distribution (transaction) and includes redress strategies such as refund, replacements, coupons, free-of-charge, repair, or discounts (Wang et al., 2011). Procedural justice refers to the service providers' policies and procedures that are ethical, consistent and unbiased. It facilitates a smooth complaint handling process and enables customers to achieve equitable outcomes (Patterson et al., 2006). Procedural justice includes timeliness and facilitation, process control, accessibility and convenience, flexibility, and the customer orientation of the procedures (del Rio-Lanza et al., 2009). Interactional justice refers to the perceived fairness of the interpersonal treatment customers receive from the service provider/employee during the complaint handling process (Tax et al., 1998). Fair interpersonal treatment is characterized by employee behavior such as being polite, respectful, courteous, friendly, honest, and informative during the customer interactions (Homburg and Furst, 2005).

\section{Perceived justice, recovery satisfaction and loyalty}

Recovery satisfaction refers to the post-recovery satisfaction with the firm's service recovery effort against those expectations (Boshoff, 2005). Extant research showed that the three justice dimensions affect satisfaction with the recovery. However, empirical evidence reveals considerable differences in the degree of the influence these dimensions have on recovery satisfaction. For instance, Homburg and Furst (2005) across a broad range of services and manufacturing industries 
found that distributive justice had a greater impact on satisfaction than procedural justice and interactional justice. On the other hand, del Rio-Lanza et al. (2009)

MMCKS showed that procedural justice has a stronger effect on recovery satisfaction than the other two justice dimensions among the cell phone users.

In contrast to the previous research findings, Karatepe (2006) found that 134 interactional justice has the largest influence on complaint satisfaction in the Hotel context followed by procedural justice and distributive justice. These differences in the relative strength of the justice dimensions have been attributed to various factors including the study context (high customer interaction vs. low customer interaction), nature of failure (process vs. outcome), research methodology (experimental design vs. field study) and the nature of satisfaction measured (transaction-specific vs. overall) (De Ruyter and Wetzels, 2000; Maxham and Netemeyer, 2002; Chebat and Slusarczyk, 2005). These contradictory findings call for further understanding of the potential sources of recovery satisfaction.

In this study, we propose that since the process is an integral part of the service, procedures and policies are considered more important than outcomes. In such case, procedural and interactional justices would make better predictors of recovery satisfaction than distributive justice. Thus, the previous discussion leads to the following hypothesis:

$\mathrm{H}_{1}$ : (a) Distributive justice, (b) Procedural justice, (c) Interactional justice are positively related to recovery satisfaction, such that procedural justice and interactional justice will have a greater impact on recovery satisfaction than distributive justice.

Loyalty reflects the customers' likelihood to continue the relationship with the service provider. Previous empirical research reveals that distributive justice, procedural justice, and interactional justice are positively related to customer loyalty. For example, De Ruyter and Wetzels (2000) examine the effects of voice (procedural justice), outcome (distributive justice) and apology (interactional justice) on customer loyalty across four service settings (Hairdresser, Dinning Café, Department Store and Bank). The findings reveal that the perception of procedural and distributive justice significantly influenced customer loyalty. Similarly, Karatepe (2006) found that greater evaluation of the three justice dimensions resulted in an increased customer loyalty. Thus, our discussion leads to the following hypothesis:

$\mathrm{H}_{2}$ : (a) Distributive justice, (b) Procedural justice, (c) Interactional justice is positively related to customer loyalty.

Prior research findings indicate that recovery satisfaction is positively related to customer loyalty (Karatepe, 2006; Orsingher et al., 2010). When customers perceive the recovery strategy as fair/just, they feel satisfied and believe that the service provider would continue providing such satisfied recovery in the future. Consequently, this enhances their loyalty towards the service provider. Thus, we develop the following hypothesis:

$\mathrm{H}_{3}$ : Recovery satisfaction is positively related to loyalty.

\section{The moderating role of failure severity}

Failure severity refers to the customers' perceived loss resulting from the magnitude or intensity of the service failure. Failure severity affects the justice dimensions as it serves as a yardstick for customer evaluation of recovery strategies (Balaji and Sarkar, 2013). Weun et al. (2004) examined the role of 
service failure severity in the relationship between distributive justice, procedural justice, interactional justice and satisfaction. The authors found a negative relationship of failure severity and distributive justice on satisfaction: the effect of distributive justice on satisfaction decreased as the customer perception of the failure severity increased. In another study, Liao (2007) found a significant interaction effect between failure severity and being courteous (interactional justice) on recovery satisfaction. It was observed that the failure severity reduces the positive effect of being courteous in predicting satisfaction. On the contrary, Sparks and Fredline (2007) demonstrated that referential explanation, a form of interactional justice will have a greater effect on satisfaction when customers experience more severe failures. Thus, the following hypothesis was proposed:

$\mathrm{H}_{4}$ : Failure severity moderates the effect of distributive justice, procedural justice, and interactional justice on recovery satisfaction.

\section{The moderating role of customer-perceived quality}

Customer-perceived quality refers to the "offer quality" of the service. According to Lapierre (2000), customer-perceived quality is the perception of reliability or durability of the product/service formed over the years. Consequently, in this study customer-perceived quality is defined as the perceived overall quality based on the past experiences with the service provider. Prior research studies show that perceived quality enhances customer value and gives the service firm a competitive advantage and long-term success (Groth and Dye, 1999). It reduces uncertainties, enhances customer satisfaction (Collier and Bienstock, 2006), and increases the likelihood to continue the relationship with service provider (Chen and Kao, 2010). While it seems plausible that perceived quality is related to service performance, research has not explicitly examined its role in service recovery evaluation. Within this study, however, we propose that customer-perceived quality has a moderating influence in the justice dimensions, failure severity and recovery satisfaction relationship. We draw on the key aspects of expectancydisconfirmation theory and mental accounting theory in hypothesizing the role of customer-perceived quality.

Expectancy-disconfirmation theory (EDT) holds that customer satisfaction is determined by the dis/confirmation that results from the prior expectations and actual performance. Thus, when the service provider's recovery efforts meet the customer expectation, positive disconfirmation occurs resulting in satisfaction. On the contrary, when the service recovery does not meet the expectations, customers are likely to experience negative disconfirmation and dissatisfaction (Kanning and Bergmann, 2009). Prior research studies suggest that customer-perceived quality is related to recovery expectations. For instance, Kelley and Davis (1994) show that perceived quality has a positive and direct influence on customer expectations of service recovery. It was argued that the perceived quality activates delivery scripts (optimistic vs. pessimistic) affecting the evaluation of recovery efforts. Furthermore, high levels of perceived quality elevate the customer commitment towards the organization and these committed customers hold elevated recovery expectations. In another study, Hess et al. (2003) examined the antecedents of customer-organizational relationships in a restaurant context. The findings revealed a significant interaction of the quality of recovery performance and recovery expectations on recovery satisfaction. The authors argued that since customers revise the attributions of the failure following the service recovery, 
perceived quality affects recovery expectations resulting in greater recovery satisfaction.

MMCKS The customers of high quality services have greater confidence in the ability of the service provider to recover from the failure satisfactorily (De Ruyter and Wetzels, 2000). Thus, an effective service recovery would have a greater influence on satisfaction for high perceived quality services as customers perceive greater confirmation and recovery value. On the contrary, customers perceive greater loss following a failure in high quality services. This coupled with greater recovery expectations could negatively affect the evaluation of perceived justice dimensions resulting in lower satisfaction (McCollough et al., 2000). Thus, customer-perceived quality can both mitigate and magnify the influence of justice dimensions on recovery satisfaction. This mitigating and magnifying effects of customer perceived quality on recovery satisfaction is influenced by the loss perceived in the service failure encounter.

According to the mental accounting theory (Thaler, 1980), people evaluate their decisions based on how they perceive or experience the outcomes. This decision choice is determined by the value function defined in terms of gains and losses relative to some reference point (Chuang et al., 2012). As customers experience greater loss in high severe failures service firms have to carry out superior or greater recovery efforts to offer the customers a gain. Therefore the difference between the loss and gain i.e. value offered to the customers reduces as failure severity increases (Weun et al. 2004; Chuang et al. 2012). Consistent with this, customers evaluate the service failures in low perceived quality and high perceived quality services as different categories of losses. They perceived greater loss in high quality services resulting in low value from the recovery efforts. On the contrary, in low quality services the loss perceived is lower and the value resulting from the recovery would be higher.

Based on our previous discussion, it can be argued for service failures in low perceived quality services the customer might experience low levels of loss. In such case, distributive justice or tangible compensation can overcome the loss experience by the customers as customers can mentally account for the loss and gain from the service failure and distributive justice. Thus, distributive justice should lead to greater confirmation and satisfaction for low perceived quality services than high perceived quality services. On the contrary for high perceived quality services, customers experience greater loss with the service failure because of the greater expectations. Thus, procedural or informational recovery could provide a better fit and confirmation for the greater loss experienced during the service failure than the tangible compensation. Ergo, the following hypothesis was proposed.

$\mathrm{H}_{5}$ : The relationship between justice dimensions, failure severity and recovery satisfaction vary across the levels of offer quality.

\section{Research methodology \\ Procedure}

Respondents were recruited from a complaint forum (www.indiaconsumer forum.org) that reported customers' mobile service failure experiences. The mobile services context was chosen because of its familiarity with the participants and the frequency of service failures. An email invitation to participate in the 
online study was sent to the members of the complaint forum. To determine the most appropriate sample, two filter questions were used. Following the filter questions "can you recollect the most recent encounter of service failure with your mobile service provider" and "what efforts did the mobile service provider carry out to recover the failure," the respondents were asked to indicate how each of the 26 statements reflected their overall experience with the mobile service provider.

The questionnaire was divided into two sections. The questions in the first section collected information on customer-perceived quality (prior to the most recent service failure experience). This allowed collecting responses on apriori quality perceptions about the service provider. In the second section, the participants responded to questions on justice dimensions, failure severity, recovery satisfaction and loyalty. Specific instructions were given to the participants for responding to the questions in each of the sections.

\section{Sample}

The final sample of 183 respondents was approximately $57 \%$ male and $43 \%$ female, with the majority of respondents between the ages of 21 and $35(42 \%)$ and 41 and 50 (27\%). Most were married (61\%) and graduate degree holders (45\%) comprised the majority of education levels. The average relationship age with the mobile service provider was approximately 26 months. A content analysis of the open-ended question revealed that the most frequently encountered failure was related to connectivity/network problem (43\%) and billing errors (25\%). A posthoc power analysis was carried out to determine the statistical power for the given sample size.

\section{Measures}

All constructs in the study were measured through multi-item scales adopted from the literature. Table I presents the source of the scales used for the constructs in the study. All items were measured on a seven-point Likert scale ranging from ' 1 'strongly disagree to '7'- strongly agree. The participants' age, gender, and education were included in the analysis as control variables. This was done to control any potential demographic effects that have been shown to affect recovery satisfaction (Palmer et al., 2000; Ndubisi and Ling 2006).

\section{Results}

\section{Validity and reliability of measurement scales}

Confirmatory factor analysis (CFA) was used to assess the construct validity. We used LISREL 8 (Joreskog and Sorbom, 1993) with maximum likelihood estimation to estimate the model. Table 1 presents the psychometric properties of the measures. One item of interactional justice with the relatively low factor loading was dropped from the analysis. The fit statistics for the seven-factor 25-item measurement model was as follows: $\chi^{2}=655.45$, d.f. $=254(p<0.05)$; Comparative Fit Index $(\mathrm{CFI})=0.97$; Normed Fit Index $(\mathrm{NFI})=0.95$; Tucker Lewis index $(\mathrm{TLI})=$ 0.96; and Root Mean Square Error of Approximation (RMSEA) = 0.07; all within the acceptable range. The composite reliability was 0.91 with the scale reliabilities being greater than or equal to 0.84 , which exceeded the recommended cutoff criteria of 0.70 . The smallest variance extracted is 0.65 , which exceeds the 0.50 
cutoff criteria (Fornell and Larcker, 1981). These findings indicate that the measures exhibit internal consistency.

Table 1. Confirmatory factor analysis of Study 1

\begin{tabular}{|c|c|c|c|c|}
\hline Constructs and source & $\Lambda$ & $\mathbf{t}$ & AVE & $\alpha$ \\
\hline \multicolumn{5}{|c|}{ Distributive Justice (DJ)(Maxham and Netemeyer, 2002) } \\
\hline $\begin{array}{l}\text { DJ1. The final outcome I received was fair given the time and } \\
\text { hassle }\end{array}$ & 0.86 & - & \multirow{4}{*}{0.68} & \multirow{4}{*}{0.89} \\
\hline $\begin{array}{c}\text { DJ2. The efforts of the service provider resulted in a positive } \\
\text { outcome for me. }\end{array}$ & 0.79 & 12.85 & & \\
\hline DJ3. Given the inconvenience, the outcome I received was fair. & 0.81 & 13.37 & & \\
\hline $\begin{array}{l}\text { DJ4. The outcome that I received in response to the problem was } \\
\text { more than fair. }\end{array}$ & 0.85 & 14.63 & & \\
\hline \multicolumn{5}{|c|}{ Procedural Justice (PJ) (Maxham and Netermeyer, 2002) } \\
\hline PJ1. The service provider responded fairly and quickly. & 0.90 & - & \multirow{4}{*}{0.78} & \multirow{4}{*}{0.87} \\
\hline PJ2. I feel the service provider responded in a timely fashion. & 0.86 & 16.85 & & \\
\hline $\begin{array}{l}\text { PJ3. I believe the service provider has fair policies and practices to } \\
\text { handle problems }\end{array}$ & 0.89 & 18.27 & & \\
\hline PJ4. I believe the service provider handled it in a fair manner & 0.89 & 14.63 & & \\
\hline \multicolumn{5}{|c|}{ Interactional Justice (IJ) (Maxham and Netemeyer, 2002) } \\
\hline IJ1. The service provider treated me in a courteous manner. & 0.97 & - & \multirow{4}{*}{0.70} & \multirow{4}{*}{0.89} \\
\hline IJ2.The service provider showed real interest in trying to be fair. & 0.89 & 21.51 & & \\
\hline $\begin{array}{l}\text { IJ3. The service provider got input from me before handling the } \\
\text { problemª. }\end{array}$ & - & & & \\
\hline $\begin{array}{l}\text { IJ4. The service provider considered my views in fixing the } \\
\text { problem }\end{array}$ & 0.60 & 9.38 & & \\
\hline \multicolumn{5}{|c|}{ Recovery Satisfaction (RS) (Maxham, 2001; Hess et al., 2003) } \\
\hline RS1. I am satisfied with the recovery efforts & 0.92 & & \multirow{4}{*}{0.87} & \multirow{4}{*}{0.96} \\
\hline $\begin{array}{l}\text { RS2. In my opinion, the service provider offered a satisfactory } \\
\text { service }\end{array}$ & 0.93 & 23.52 & & \\
\hline $\begin{array}{l}\text { RS3. As a whole, I am satisfied with the service provider's } \\
\text { recovery efforts }\end{array}$ & 0.95 & 25.23 & & \\
\hline RS4. I am pleased with the service provider's efforts & 0.93 & 23.43 & & \\
\hline \multicolumn{5}{|c|}{ Customer loyalty (CL) (Lam et al., 2004; Sousa and Voss, 2009) } \\
\hline CL1. Intention to re-use the service provider & 0.89 & - & \multirow{4}{*}{0.80} & \multirow{4}{*}{0.94} \\
\hline $\begin{array}{l}\text { CL2. Intention to recommend the service provider to friend or } \\
\text { family }\end{array}$ & 0.97 & 23.52 & & \\
\hline CL3. I would say positive things about the service provider & 0.95 & 21.94 & & \\
\hline $\begin{array}{l}\text { CL4. I consider this service provider as my first choice for the } \\
\text { mobile services }\end{array}$ & 0.76 & 13.33 & & \\
\hline \multicolumn{5}{|c|}{ Customer-perceived Quality (PQ)( Blocker et al., 2011) } \\
\hline PQ1. To exceed the standards for quality services & 0.78 & - & \multirow{3}{*}{0.65} & \multirow{3}{*}{0.84} \\
\hline PQ2. To consistently provide quality services over time & 0.86 & 12.22 & & \\
\hline PQ3. To provide excellent quality services & 0.75 & 10.55 & & \\
\hline \multicolumn{5}{|l|}{ Failure Severity (FS) (Smith et al.,1999) } \\
\hline FS1. Major problem & 0.95 & - & & \\
\hline FS2. Big inconvenience & 0.80 & 13.99 & 0.74 & 0.89 \\
\hline FS3. Major aggravation & 0.82 & 14.79 & & \\
\hline
\end{tabular}

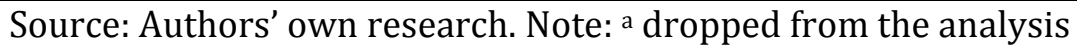

To assess discriminant validity, the average variance extracted values for each measure was compared with the squared correlation between each pair of constructs. Discriminant validity was supported as the squared correlation between the constructs did not exceed the individual average variance extracted values (Fornell and Larcker, 1981). Table 2 reports the descriptive statistics and correlations. 
Table 2. Descriptive statistics and correlations

\begin{tabular}{|c|c|c|c|c|c|c|c|c|}
\hline & Mean (SD) & DJ & PJ & IJ & RS & CL & $P Q$ & FS \\
\hline DJ & $3.36(1.50)$ & & & & & & & \\
\hline PJ & $3.50(1.65)$ & $0.61^{* * *}$ & - & & & & & \\
\hline IJ & $3.68(1.60)$ & $0.59^{* * *}$ & $0.69^{* * *}$ & - & & & & \\
\hline RS & $4.13(1.85)$ & $0.48^{* * *}$ & $0.55^{* * *}$ & $0.45^{* * *}$ & - & & & \\
\hline CL & $3.84(1.58)$ & $0.57^{* * *}$ & $0.61^{* * *}$ & $0.59^{* * *}$ & $0.68^{* * *}$ & - & & \\
\hline$P Q$ & $4.26(1.40)$ & $0.34^{* * *}$ & $0.36^{* * *}$ & $0.33^{* * *}$ & $0.43^{* * *}$ & $0.52^{* * *}$ & - & \\
\hline FS & $4.69(1.76)$ & $-0.29^{* * *}$ & $-0.25^{* * *}$ & $-0.18^{* * *}$ & $-0.46^{* * *}$ & $-0.15^{* *}$ & $-0.40^{* *}$ & - \\
\hline
\end{tabular}

As we used self-reported data from a single source of information, there existed the potential for the common method variance to bias the results. We examined the potential threat of common method variance through the Harmon's one factor model and the latent methods factor approach as suggested by Podsakoff et al. (2003). The results of these analysis provided support that method variance was not a potential source of error in the measurement model.

\section{Hypotheses testing}

To test $\mathrm{H}_{1}$ and $\mathrm{H}_{2}$, we examined the effects of the three justice dimensions on recovery satisfaction and loyalty. As suggested by Aiken and West (1991), regression analyses were carried out in which the control variables were first entered and then followed by the three justice dimensions to examine the hypothesized main effects. As the control variables - age (RS: $p=0.97$; CL: $p=$ 0.27 ), gender (RS: $p=0.60$; CL: $p=0.89$ ) and education (RS: $p=0.62$; CL: $p=0.92$ ) did not have significant effect, they were excluded from further analysis.

The regression analysis show that distributive justice $(\beta=0.19, p<0.05)$, procedural justice $(\beta=0.29, p<0.01)$ and interactional justice $(\beta=0.26, p<0.01)$ have a positive significant effect on recovery satisfaction. $\mathrm{H}_{1}$ was supported as procedural justice and interactional justice had greater effect on recovery satisfaction than distributive justice. For loyalty, only interactional justice was found to have a positive and significant effect $(\beta=0.29, p<0.01)$, provides support for $\mathrm{H}_{2 c}$.

$\mathrm{H}_{3}$ predicted the relationship between satisfaction and loyalty. This hypothesis was supported as satisfaction had a positive significant effect on loyalty $(\beta=0.35, p<0.01)$.

The moderation effect of failure severity on recovery satisfaction was examined with hierarchical regression analysis. The moderation effect of failure severity on recovery satisfaction was examined with hierarchical regression analysis. The justice dimensions and failure severity were mean centered, and the interaction terms were created by multiplying the centered variables (Aiken and West, 1991). Table 3 (Model 1 and 2) present the summary of the moderated regression analysis. The results reveal that failure severity moderately affects the influence of procedural justice on recovery satisfaction $(\beta=0.13, p<0.10)$. The slope analysis shows that for less severe failures, greater procedural justice results in greater satisfaction, while no significant difference was observed for the high 
severe failures in the procedural justice and recovery satisfaction relationship. This provides support for $\mathrm{H}_{4 \mathrm{~b}}$.

MMCKS

Table 3. Summary of the moderated regression analyses on recovery satisfaction

\begin{tabular}{|c|c|c|c|c|}
\hline & $\begin{array}{c}\text { Model } 1 \\
\beta\end{array}$ & $\begin{array}{c}\text { Model } 2 \\
\beta\end{array}$ & $\begin{array}{c}\text { Model } 3 \\
\beta\end{array}$ & $\begin{array}{c}\text { Model } 4 \\
\beta\end{array}$ \\
\hline \multicolumn{5}{|l|}{ Main effects } \\
\hline Distributive justice (DJ) & $0.13^{*}$ & 0.09 & 0.08 & -0.02 \\
\hline Procedural justice (PJ) & $0.22^{* *}$ & $0.18^{* *}$ & $0.15^{*}$ & $0.14^{*}$ \\
\hline Interactional justice (IJ) & $0.27 * * *$ & $0.24^{* *}$ & 0.08 & $0.14^{*}$ \\
\hline Failure severity (FS) & $-0.33^{* * *}$ & $-0.39 * * *$ & $-0.28^{* * *}$ & $-0.25^{* * *}$ \\
\hline Customer perceived quality (PQ) & - & & $0.46^{* * *}$ & $0.47^{* * *}$ \\
\hline \multicolumn{5}{|l|}{ Two-way interaction } \\
\hline DJ $x \mathrm{FS}$ & - & 0.07 & - & $0.22 *$ \\
\hline $\mathrm{PJ} \times \mathrm{FS}$ & - & $0.13^{*}$ & - & -0.11 \\
\hline IJ $x$ FS & - & 0.02 & - & -0.09 \\
\hline \multicolumn{5}{|l|}{ Three-way interaction } \\
\hline DJ $x$ FS $\times$ PQ & - & - & - & $-0.21 * * *$ \\
\hline $\mathrm{PJ} \times \mathrm{FS} \times \mathrm{PQ}$ & - & - & - & $0.26^{* *}$ \\
\hline IJ $x$ FS x PQ & - & - & - & -0.11 \\
\hline $\mathrm{R}^{2}$ & 0.53 & 0.57 & 0.65 & 0.70 \\
\hline Model F & $51.26^{* * *}$ & $33.01^{* * *}$ & $69.54 * * *$ & $26.57^{* * *}$ \\
\hline
\end{tabular}

Source: Authors' own research. Note: ${ }^{*} p<0.10, t=1.65,{ }^{* *} p<0.05, t=1.96,{ }^{* * *} p<.0 .01, t=$

To examine $\mathrm{H}_{5}$, moderated hierarchical regression analysis with three-way interactions (justice dimensions by failure severity by perceived quality) was carried out. The Model 3 and 4 in Table 3 present the results of the regression analysis. The results reveal a positive and significant three-way interaction of procedural justice, failure severity and perceived quality on recovery satisfaction $(\beta=0.21, p<0.05)$. This provides support for $\mathrm{H}_{5 \mathrm{~b}}$. To better understand the nature of interaction obtained in the regression analysis, the slope difference test (Aiken and West, 1991) at \pm 1 standard deviation from the mean of procedural justice was applied. The slope difference results, as shown in Figure 2, reveal significant differences when comparing the effects of procedural justice, failure severity and perceived quality on recovery satisfaction. Specific contrast indicate that the low failure severity/high perceived quality slope is significantly different than that in the high failure severity/high perceived quality condition $(t=3.17 ; p<0.01)$ as well as the low failure severity/low perceived quality condition $(t=-2.00, p<$ 0.05). As expected, the positive sloping line in the high failure severity/high 
perceived quality condition suggests that when consumers experience failures of greater magnitude in high perceived quality services, high procedural justice results in greater recovery satisfaction. Conversely, the downward slopping low failure severity/high perceived quality shows that providing high procedural justice for less severe failure does not accentuate recovery satisfaction for high perceived quality services.

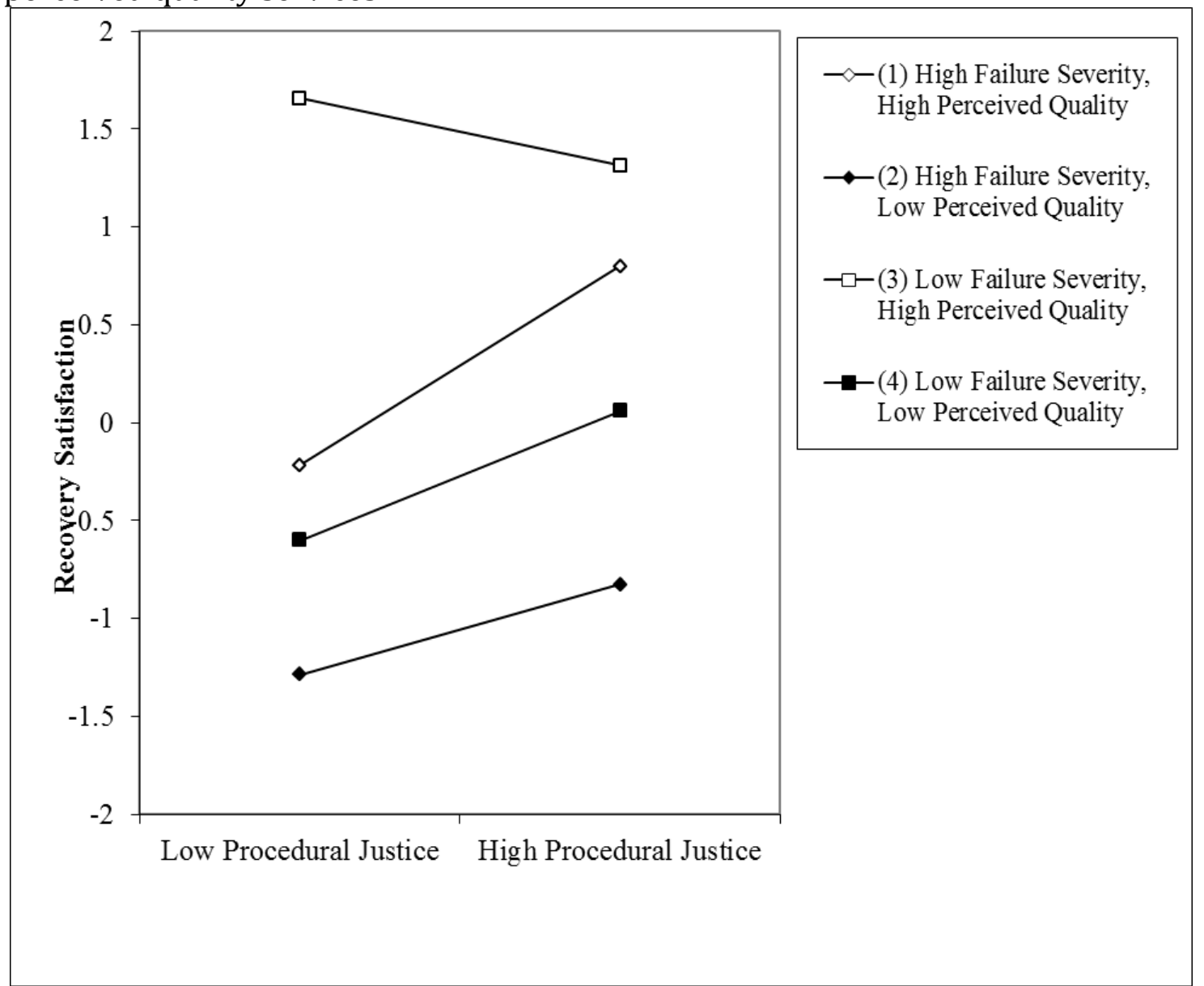

Figure 1. Three-way interaction of procedural justice $\mathrm{x}$ failure severity $\mathrm{x}$ offer quality

Source: Authors' own research.

The three-way interaction of distributive justice, failure severity and perceived quality has a moderate negative impact on recovery satisfaction $(\beta=-$ $0.18, p<0.10$ ). This finding provides support for $\mathrm{H}_{5 \mathrm{a}}$. The slope difference analysis, as shown in Figure 2, reveal interesting findings. We observed a significant difference between high failure severity/low perceived quality and low failure severity/low perceived quality condition $(t=2.24, p<0.05)$. The upward slopping high failure severity/low perceived quality shows that providing high distributive justice for high failure severity increases recovery satisfaction for low perceived quality services. On the contrary, the results indicate that for high perceived quality services, distributive justice does not provide differentiating recovery satisfaction for low and high failure severity conditions. These findings present important implications for service managers in designing the recovery strategy for service firms of high perceived quality and low perceived quality. 


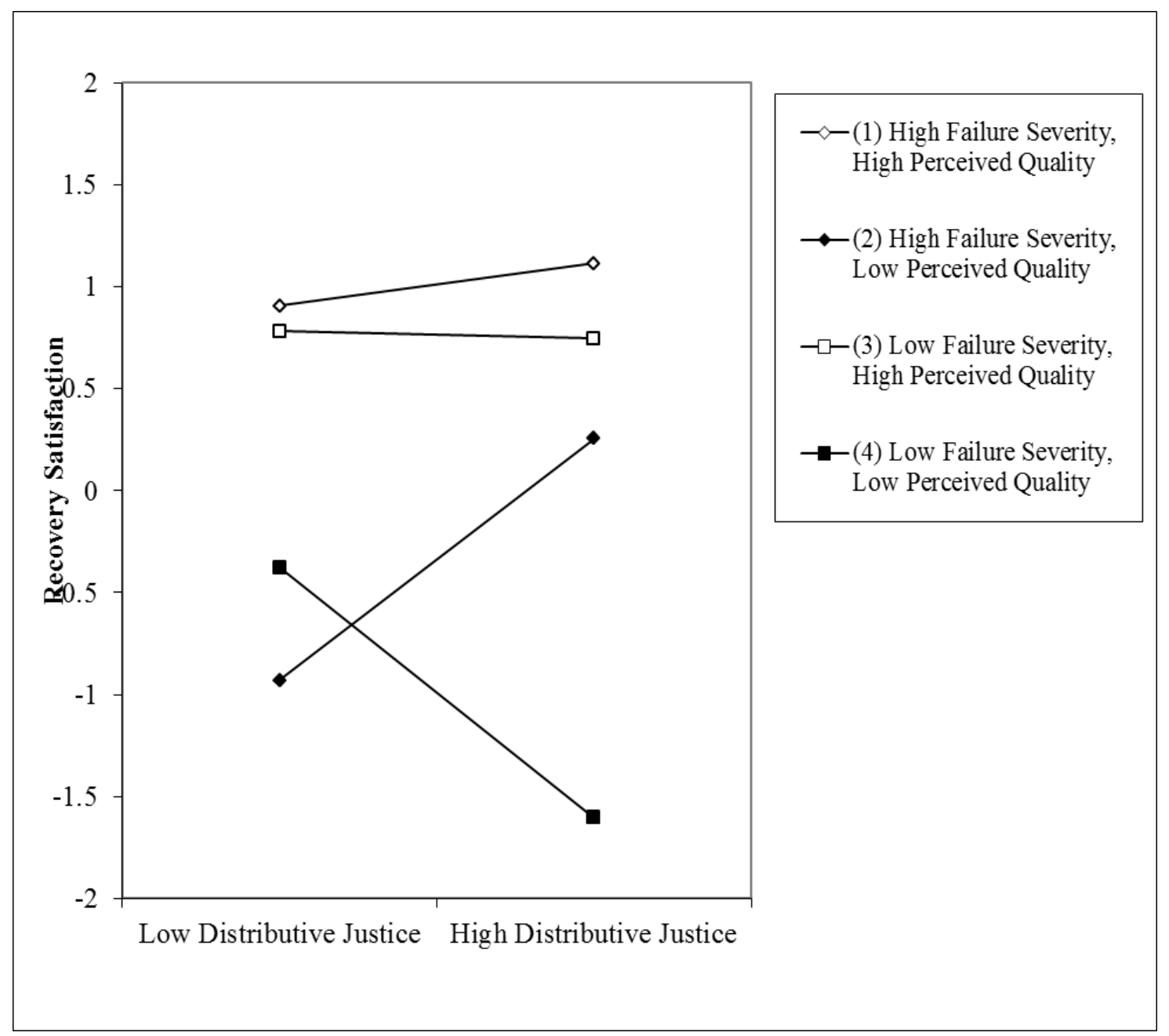

Figure 2. Three way interaction of distributive justice $\mathrm{x}$ failure severity $\mathrm{x}$ offer quality Source: Authors' own research.

\section{Discussion}

The purpose of this study was to examine the role of customer-service quality in affecting the linkages between service failure severity, perceived justice dimension, satisfaction and loyalty. The findings extend prior research in service failure and recovery area by providing evidence for the significant role of customer-perceived quality in shaping the effects of perceived justice and failure severity on recovery satisfaction.

We found that all three perceived justice dimensions i.e. distributive, procedural, and interactional justice significantly affect recovery satisfaction. Additionally, we found that procedural and interactional justices affect recovery satisfaction the most, in contrast to the findings of Chebat and Slusarczyk (2005) in the retail banking and Kim et al. (2009) in the hotel context. A possible explanation for the same could be the characteristics of the mobile services industry. As customer interactions with the mobile service provider are infrequent and mostly involve service failure complaints, the perception of interpersonal treatment during complaint handling plays a key role in recovery satisfaction. Further, the nature of complaints in the mobile service industry typically involves connectivity or communication failures. Thus, accessibility, timeliness and flexibility of the complaint handling procedures positively influence customers' perception of 
recovery satisfaction. Further, interactional justice was found to have a significant impact on the outcome variable of loyalty. This finding is consistent with the study of Chebat and Slusarczyk (2005). As customer interactions with the service provider are mostly indirect (through mobile phone), interactional justices cues play a significant role in the customers' decision to stay loyal. Poor or inadequate interactions violate the norm of social exchange and reciprocity leading to exit behaviors.

The findings show that service failure severity has a significant negative relationship in the recovery satisfaction. As such, customers who experience service failures of high severity are likely to exhibit lower recovery satisfaction than those who experience service failures of low severity. This is consistent with the findings of Smith et al. (1999). The results also show that failure severity moderates the relationship between procedural justice and recovery satisfaction; the positive relationship of procedural justice on recovery satisfaction is alleviated by high failure severity. As procedural justice is a basic requirement in the service recovery, low levels of procedural justice might generate negative emotions leading to customer dissatisfaction. The insignificant moderating relationships of distributive and interactional justice with failure severity implies that while perceived fairness of the redress and interpersonal treatment are important elements of service recovery, failure severity will not weaken the positive relationship of failure severity.

Finally, the study findings demonstrated that customer-perceived quality moderates the relationship between justice dimensions, failure severity and recovery satisfaction. However, the moderating role of perceived quality was found only for procedural justice and distributive justice. It was inferred from the results that procedural justice-related recovery efforts are more effective for high perceived quality than low perceived quality services. Thus, high customerperceived quality can accentuate the effect of procedural justice on recovery satisfaction for high severe failures. This provides empirical support for the mitigating effect of perceived quality. For low quality services, as shown in Figure II, high distributive justice has a significant positive effect on recovery satisfaction for failure severity of high level. Thus, it was inferred that distributive-related justice outcomes are more effective for low perceived quality services than high perceived quality services. In summary, our findings suggest that "one-size-fits-all" strategy may not work in recovering satisfactorily. The service provider should identify and meet the customer expectations with the appropriate recovery strategy depending on the customer-perceived quality levels.

\section{Managerial implications}

The results of this study suggest that service managers should formulate appropriate recovery strategies and employ these strategies to effectively address the failure experienced by the customers. This can be achieved by identifying the different types of service failures and categorizing them into broad categories. Then, suitable recovery efforts can be offered to overcome the negative experience of service failure. According to the findings of the present study, choosing the right type of recovery strategy can mitigate the undesirable effects of failure severity in predicting recovery strategy. While the results reinforce the importance of all three justice dimensions in the recovery strategy in predicting customer 
satisfaction, evaluation of customer-perceived quality affects the role of MMCKS distributive justice and procedural justice in influencing recovery outcomes. More specifically, the results reveal that for low perceived quality services, distributive justice can enhance the recovery satisfaction for high severe failures. On the

144 contrary, procedural justice results in greater satisfaction for high severe failures in high perceived quality services than low perceived quality services. Thus, policies and procedures can revitalize satisfaction following a severe failure in service firms offering high perceived quality, while refund or compensation would mitigate the impact of severe failures in low perceived quality services. This finding offers valuable insights for managers into the means by which customers' perceive service failures and recovery expectations for service firms with varying perceived quality. By understanding the nature of failures in high and low perceived quality services, the managers of the service firms can better judge the type of recovery efforts that could make up for the losses experienced by the customers. Thus, service managers should be careful in employing the different recovery strategies as satisfaction-enhancing strategy. A proper fit between the perceived quality and recovery strategy results in increased satisfaction and loyalty intentions.

\section{Limitations and future research directions}

The contributions of this study must be considered in light of the limitations. First, is our choice of memory as a source of service failure recall? This could potentially affect the findings as memory bias could affect the recall of the service failure. Second, bias could exist in the way the responses on customer-perceived quality were collected in the study. This could possibly affect the findings of the study. Future studies could use mock service environments and immersive designs to elicit more natural responses. Third, the study was carried out in moderate and high service settings of mobile services and airline services (Han et al., 2008). Future research could replicate the study in other service settings like hospitality or restaurant setting where the customer involvement is high and the customerprovider interactions take place more directly. Finally, we recommend future research studies to consider customer personality traits in examining the relationship between perceived justice and recovery satisfaction. As justice is in the eye of the beholder, managers need to understand how customers' evaluation of recovery strategies is affecting customer satisfaction.

\section{References}

Aiken, L.S. and West, S.G. (1991), Multiple regression: Testing and interpreting interactions, Sage Publications, Thousand Oaks.

Andreassen, T.W. (2000), "Antecedents to satisfaction with service recovery", European Journal of Marketing, Vol. 34, No. 1/2, pp. 156-175.

Balaji, M.S. and Sarkar, A. (2013), "Does successful recovery mitigate failure severity?: A study of the behavioral outcomes in Indian context", International Journal of Emerging Markets, Vol. 8, No. 1, pp. 65-81.

Baron, R.M. and Kenny, D.A. (1986), "The moderator-mediator variable distinction in social psychological research: Conceptual, strategic, and statistical considerations", Journal of Personality and Social Psychology, Vol. 51, No. 6, pp. 1173-1182. 
Boshoff, C., (2005) "A re-assessment and refinement of RECOVSAT: An instrument to measure satisfaction with transaction-specific service recovery", Managing Service Quality, Vol. 15 No. 5, pp. 410 - 425.

Brady, M.K., Cronin, J.J., Fox, G.L. and Roehm, M.L. (2008), "Strategies to offset performance failures: The role of brand equity", Journal of Retailing, Vol. 84, No. 2, pp. 151-164.

Chebat, J. and Slusarczyk, W. (2005), "How emotions mediate the effects of perceived justice on loyalty in service recovery situations: An empirical study", Journal of Business Research, Vol. 58, No. 5, pp. 664-673.

Chen, C. and Kao, Y. (2010), "Relationships between process quality, outcome quality, satisfaction, and behavioural intentions for online travel agenciesevidence from Taiwan", The Service Industries Journal, Vol. 30, No. 12, pp. 2081-2092.

Chuang, S., Cheng, Y., Chang, C. and Yang, S. (2012), "The effect of service failure types and service recovery on customer satisfaction: A mental accounting perspective", The Service Industries Journal, Vol. 32, No. 2, pp. 257-271.

Collier, J.E. and Bienstock, C.C. (2006), "Measuring service quality in e-retailing", Journal of Service Research, Vol. 8, No. 3, pp. 260-275.

D'Amico, E.J., Neilands, T.B. and Zambarano, R. (2001), "Power analysis for multivariate and repeated measures designs: A flexible approach using the SPSS MANOVA procedure", Behavior Research Methods, Vol. 33, No. 4, pp. 479-484.

de Matos, C.A., Vieira, V.A. and Veiga, R.T. (2012), "Behavioural responses to service encounter involving failure and recovery: The influence of contextual factors", The Service Industries Journal, Vol. 32, No. 12, pp. 22032217.

De Ruyter, K. and Wetzels, M. (2000), "Customer equity considerations in service recovery: A cross-industry perspective", International Journal of Service Industry Management, Vol. 11, No. 1, pp. 91-108.

del Río-Lanza, A.B., Vázquez-Casielles, R., and Díaz-Martín, A.M. (2009), "Satisfaction with service recovery: Perceived justice and emotional responses", Journal of Business Research, Vol. 62, No. 8, pp. 775-781.

Fornell, C., and Larcker, D.F. (1981), "Evaluating structural equation models with unobservable variables and measurement error", Journal of Marketing Research, Vol. 18, No. 1, pp. 39-50.

Groth,J.C. and Dye, R.T. (1999) "Service quality: perceived value, expectations, shortfalls, and bonuses", Managing Service Quality, Vol. 9 No. 4, pp.274 286

Han, X., Kwortnik, R.J., and Wang, C. (2008), "Service loyalty an integrative model and examination across service contexts", Journal of Service Research, Vol. 11, No. 1, pp. 22-42.

Hess Jr, R.L., Ganesan, S., and Klein, N.M. (2003), "Service failure and recovery: The impact of relationship factors on customer satisfaction", Journal of the Academy of Marketing Science, Vol. 31, No. 2, pp. 127-145.

Homburg, C. and Fürst, A. (2005), "How organizational complaint handling drives customer loyalty: An analysis of the mechanistic and the organic approach", Journal of Marketing, Vol. 69, No. 3, pp. 95-114.

Jöreskog, K.G. and Sörbom, D. (1993), LISREL VIII: User's reference guide, Scientific Software International, Chicago. 
MMCKS Kanning, U.P. and Bergmann, N. (2009) "Predictors of customer satisfaction: testing the classical paradigms", Managing Service Quality, Vol. 19, No. 4, pp. $377-390$

Karatepe, O.M. (2006), "Customer complaints and organizational responses: The effects of complainants' perceptions of justice on satisfaction and loyalty", International Journal of Hospitality Management, Vol. 25, No. 1, pp. 69-90.

Kelley, S.W., and Davis, M.A. (1994), "Antecedents to customer expectations for service recovery", Journal of the Academy of Marketing Science, Vol. 22, No. 1, pp. 52-61.

La, S. and Choi, B. (2012), "The role of customer affection and trust in loyalty rebuilding after service failure and recovery", The Service Industries Journal, Vol. 32, No. 1, pp. 105-125.

Lam, S.Y., Shankar, V., Erramilli, M.K. and Murthy, B. (2004), "Customer value, satisfaction, loyalty, and switching costs: An illustration from a business-tobusiness service context", Journal of the Academy of Marketing Science, Vol. 32, No. 3, pp. 293-311.

Lapierre, J. (2000), "Customer-perceived value in industrial contexts", Journal of Business and Industrial Marketing, Vol. 15, No. 2/3, pp. 122-145.

Liao, H. (2007), "Do it right this time: The role of employee service recovery performance in customer-perceived justice and customer loyalty after service failures", Journal of Applied Psychology, Vol. 92, No. 2, pp. 475-489.

Lin, H., Wang, S. and Chang, L. (2011) "Consumer responses to online retailer's service recovery after a service failure: A perspective of justice theory", Managing Service Quality, Vol. 21 No. 5, pp. 511 - 534.

Maxham III, J.G. and Netemeyer, R.G. (2002), "A longitudinal study of complaining customers' evaluations of multiple service failures and recovery efforts", The Journal of Marketing, Vol. 66, No. 4, pp. 57-71.

Maxham, J.G. (2001), "Service recovery's influence on consumer satisfaction, positive word-of-mouth, and purchase intentions", Journal of Business Research, Vol. 54, No. 1, pp. 11-24.

McColl-Kennedy, J.R. and Sparks, B.A. (2003), Application of fairness theory to service failures and service recovery. Journal of Service Research, Vol. 5, No. 3, pp. 251-266.

McCollough, M.A., Berry, L.L. and Yadav, M.S. (2000), "An empirical investigation of customer satisfaction after service failure and recovery", Journal of Service Research, Vol. 3, No. 2, pp. 121-137.

Ndubisi, N.O. and Ling, T.Y. (2006), Complaint behaviour of Malaysian consumers", Management Research News, Vol. 29, No. 1/2, pp. 65-76.

Orsingher, C., Valentini, S. and de Angelis, M. (2010), "A meta-analysis of satisfaction with complaint handling in services", Journal of the Academy of Marketing Science, Vol. 38, No. 2, pp. 169-186.

Palmer, A., Beggs, R. and Keown-McMullan, C. (2000), "Equity and repurchase intention following service failure", Journal of Services Marketing, Vol. 14, No. 6, pp. 513-528.

Patterson, P.G., Cowley, E. and Prasongsukarn, K. (2006), "Service failure recovery: The moderating impact of individual-level cultural value orientation on perceptions of justice", International Journal of Research in Marketing, Vol. 23, No. 3, pp. 263-277. 
Podsakoff, P.M., MacKenzie, S.B., Lee, J. and Podsakoff, N.P. (2003), "Common method biases in behavioral research: A critical review of the literature and recommended remedies", Journal of Applied Psychology, Vol. 88, No. 5, pp. 879-903.

Sajtos, L., Brodie, R.J. and Whittome, J. (2010), "Impact of service failure: The protective layer of customer relationships", Journal of Service Research, Vol. 13, No 2, pp. 216-229.

Sengupta, A.S., Balaji, M.S. and Krishnan, B.C. (2014), "How customers cope with service failure? A study of brand reputation and customer satisfaction", Journal of Business Research, Vol. 68, No. 3, pp. 665-674.

Schoefer, K. and Ennew, C. (2005), "The impact of perceived justice on consumers' emotional responses to service complaint experiences", Journal of Services Marketing, Vol. 19, No. 5, pp. 261-270.

Smith, A.K. and Bolton, R.N. (1998), "An experimental investigation of customer reactions to service failure and recovery encounters paradox or peril?" Journal of Service Research, Vol. 1, No. 1, pp. 65-81.

Sousa, R. and Voss, C.A. (2009), "The effects of service failures and recovery on customer loyalty in e-services: An empirical investigation", International Journal of Operations and Production Management, Vol. 29, No. 8, pp. 834864.

Sparks, B. and Fredline, L. (2007), "Providing an explanation for service failure: Context, content, and customer responses", Journal of Hospitality and Tourism Research, Vol 31, No 2, pp. 241-260.

Suh, J., Janda, S. and Seo, S. (2006), "Exploring the role of culture in trust development with service providers", Journal of Services Marketing, Vol. 20, No. 4, pp. 265-273.

Tax, S.S., Brown, S.W. and Chandrashekaran, M. (1998), "Customer evaluations of service complaint experiences: Implications for relationship marketing", The Journal of Marketing, Vol. 62, No. 2, pp. 60-76.

Wang, Y., Wu, S., Lin, H. and Wang, Y. (2011), "The relationship of service failure severity, service recovery justice and perceived switching costs with customer loyalty in the context of e-tailing", International Journal of Information Management, Vol. 31, No. 4, pp. 350-359.

Weun, S., Beatty, S.E. and Jones, M.A. (2004), "The impact of service failure severity on service recovery evaluations and post-recovery relationships", Journal of Services Marketing, Vol. 18, No. 2, pp. 133-146. 